\title{
Law Student Information Seeking, and Understanding of Citation, Common Knowledge, and Plagiarism
}

\author{
Kris Helge, J.D., Ph.D. \\ Assistant Dean, Academic Engagement; Texas Woman’s University
}

\begin{abstract}
This study examines how previous information literacy training before and during law school, law student gender, law student age, where one attends law school, year in law school, and previously obtained education affects law students' selection of information sources, their understanding of common knowledge, and their decision of whether or not to give attribution to these sources. Zipf's paradigm that states humans perform the least amount of work to complete the greatest tasks guides the analysis of this study. To examine these factors, the researcher completes six focus groups and disseminates an online survey via SurveyMonkey. The data collected from these research endeavors suggests that law students do exhibit some differences in understanding of citation and citation behavior based on age and their year in law school. They also exhibit some differences regarding their understanding of common knowledge based on their year in law school, where they received their information literacy training, and where they attend law school. Yet, no statistically significant differences are discovered regarding where one attends law school and law student citation and source selection. Further this study reveals law students may tend to follow Zipf's paradigm and seek the path of least resistance to accomplish law school assignments.
\end{abstract}

Keywords

Information source, plagiarism, common knowledge, citation, law student.

\section{INTRODUCTION}

In today's information world, information literacy training is increasingly more important to prepare people for professional work where they access, utilize, and have to know how to credit diverse information sources. Such training is now a part of most academy curriculums at educational levels from elementary school to graduate school. Information literacy training is imperative because students are seeking out information via traditional print sources and increasingly more via digital mediums. Some of these digital mediums include blogs, social media, and websites. Due to the increase in research via digital platforms, it is imperative academies offer to students training on how to decipher which sources are valid and which are not. Also, students need to be taught what material to cite and what material not to cite. Overall, information literacy pedagogy needs to address how students may ethically obtain, use, and credit both valid print and electronic information sources. 
Due to the need to address students' access, use, and citation of information, an increased demand is placed on high school teachers, and professors at the college and graduate levels to rethink how information literacy is taught. A few years ago most professors and high school teachers might have discouraged the use and citation of digital sources, out of fear that such content may not be reliable. However, to save money, many publishers are moving to digital platforms, and many schools and universities are purchasing more digital content, rather than print content. Therefore, all instructors at the academy may want to rethink what digital content is reliable and acceptable for students to utilize, and how to inculcate students with digital literacy skills that enable students to navigate, select, and cite valid and reliable digital information. This metacognition and pedagogical reformation in regard to how digital content is perceived and taught to students needs to be completed at the K-12, college, and graduate school levels. To understand what information current students are presently accessing, whether they understand the concepts of common knowledge, plagiarism, and citation, this study utilizes law students for its population. To comprehend the potential impacts of this study, it is important to convey why information literacy is important in the law school environment.

\section{WHY ANALYSIS OF INFORMATION LITERACY TRAINING IS IMPORTANT}

Law schools place a heavy emphasis on information literacy, as all law schools are bound by the American Bar Association (ABA) to offer valid and reliable information literacy training. The $\mathrm{ABA}$ requires all accredited law schools to establish learning outcomes to reach successful research and writing outcomes for law students (Partin \& Wise, 2016). The ABA also mandates that all law schools evaluate and reevaluate their educational programs and to make appropriate pedagogical changes to improve the curriculum (Partin \& Wise, 2016). Due to the changes in what information tools law students are inclined to use for research, such as using more digital content, many law schools have created internal policy to ensure they meet ABA standards. The University of Florida Law School and other law schools recommend their research and writing classes teach students to properly interpret legal citations, successfully find legal sources, identify secondary sources that would offer support to primary sources, develop the ability to create a research plan, be able to use finding tools successfully, and give proper citation to used sources (Partin \& Wise, 2016).

Numerous law schools have these or similar goals for their research and writing classes. However, current law students grow up using more general finding tools to locate movie times, automobile prices, or driving directions. They are successfully finding non-legal information with finding tools such as Google or other search engines. Thus, some have a false sense of confidence in finding all information they need using Google or another search engine. It is imperative law schools tweak their legal research and writing curriculum to educate law students that when using Google, or another search engine, one is not finding information from the deep web where a plethora of valid and reliable information resides. Not only do they need to inform students how to cite, how to locate information sources..., the instructors also need to educate law students on the differences between locating information from the Internet and locating information via valid and reliable legal databases such as Westlaw and LexisNexis. They need to inculcate students with skills to decipher what is a valid electronic site and what is not. Law 
students also need to learn which electronic sites may they cite without losing credibility, and which electronic sources are not appropriate to cite? In order to not lose credibility, law students need to obtain information from reliable sites.

Partin and Wise (2016) discuss that when performing legal research one needs to seek out reliable information sources, and research plans need to be updated frequently to ensure reliability. In other words, a law student who is seeking information about divorce in Texas should realize that the more reliable available information resides in LexisNexis or Westlaw, not on the shallow Internet. Also, simply because a student obtains some relevant information by using Google, this does not mean the student's research is over. Instead, his or her research plan should be tweaked to then go research in Westlaw or LexisNexis, and the research has just begun.

To help examine the current state of law students' understanding of information literacy, this study scrutinizes whether law students understand how to locate valid information sources, whether they are aware of the guidance available to them to help them cite electronic and print sources, whether they know how to properly cite, and what is their primary research tool (e.g., Google or Westlaw).. The findings of this study offer information to legal research and writing professors and professors who teach in other substantive areas regarding how law students seek out legal information, whether they cite utilized information, and if they understand what common knowledge and plagiarism are. Based on these findings, legal research and writing professors may be able to offer new information literacy instruction or tools to their students that help their students gain a better understanding of what is a valid electronic search tool, what information to cite, and what is common knowledge. Thus, these results may enable law professors to tweak their pedagogical approach to teaching information literacy. The findings of this study may also be extrapolated to other substantive areas to gain insight regarding student information seeking behavior, and student understanding of citation and common knowledge, which are all a part of information literacy. Because these findings may offer such guidance, it is important to adequately and more granularly define some of the various elements that make up information literacy.

\section{WHAT ENCOMPASSES INFORMATION LITERACY}

Information literacy encompasses the above-mentioned factors such as understanding of common knowledge, citation, plagiarism and source selection. To better understand each of these topics and information literacy, each require proper explanation. The American Association of College of Research Libraries (AACRL) offers standards for all colleges and universities to follow to help ensure ethical and efficient access and use of information by students, staff, and faculty. The AACRL offers helpful definitions of concepts to help better understand what they

mean. The AACRL defines information literacy as "a set of abilities requiring individuals to recognize when information is needed and to have an ability to locate, evaluate and use effectively the needed information" (Association of College and Research Libraries, ACRL, 2000). The AACRL further notes that part of appropriate information literacy training includes the ability to use the information effectively, to access needed information effectively and efficiently, and to access and use information ethically and legally (ACRL, 2000). Information 
literacy training includes teaching students how to cite other creators' works and uses information ethically and legally. Such training also encompasses teaching students the importance of giving citations to sources so that readers may locate information, thus complying with the ACRL's definition suggesting information literacy includes empowering access to information and using it effectively. A good summary of information literacy as it relates to this study is to teach students how to select valid and reliable information, realize when a citation is and is not required to provide effective and efficient access to information, and to ensure ethical use of information. A couple of factors explored in this study include whether law students understand the difference between information that is common knowledge and that is not, and whether law students understand plagiarism. It is necessary to clearly describe common knowledge and plagiarism, as each of these terms fit within the information literacy concept

\section{Common Knowledge}

Empirical research defines common knowledge as any information that is well known by all and is so well known it does not require a reference (Mahmood, Mahmood, Khan, \& Malik, 2010). Common knowledge is also defined as information the average, educated reader accepts as valid without needing to be referred to an information source to look it up (Academic Integrity at MIT, 2014). Thus, for a group of law students, an example of common knowledge in the legal field is the statement that "one makes his or her argument at a courthouse to defend his or her case." Such a statement does not need to be cited, even if one reads this statement in a book, on the Internet, or elsewhere, because it is common knowledge in the legal field, and most likely everywhere, that people make their legal arguments to judges in a courtroom. They do not make their legal arguments in a barn, at a mall, or in a football stadium.

Common knowledge is further defined by the particular group of people or audience with like interests, such as law students or attorneys. Attorneys practicing law in the United States probably consider it common knowledge that one may legally have the right to counsel in a criminal proceeding, but not always in a civil proceeding. This is probably common knowledge for attorneys practicing law in the United States. Such a statement may not be common knowledge for professional tennis players who play tennis in the United States. The statement that one may legally have the right to counsel in a criminal proceeding, but not always in a civil proceeding may be common for one group of attorneys and not common knowledge for another group of professional tennis players.

To further illustrate the point, an example of information that is not common knowledge for law students, and that requires citation consists of "one may successfully obtain an annulment in Texas if one can prove his or her marriage was completed by fraud." Even though law students are studying law in law school, they cannot be expected to know every single law. Many law students do not commonly know this fact, and would need to look this information up in a legal source and then give that source proper citation. When including this statement in a written text, brief, petition, or other legal document, it must be cited. If law students have a correct understanding of what is and is not common knowledge they will know how to properly cite and avoid plagiarism. To examine which factors affect law students' understanding of plagiarism, this study needs to properly identify plagiarism. 
Plagiarism

Plagiarism is an esoteric topic, and because of its obscure nature the actual meaning of the word is often confusing. Mahmood et al. (2010) noted plagiarism is somewhat like pornography in that one knows it when they see it, but it is difficult to define. Empirical studies define plagiarism as taking and using another person's thoughts, writing, inventions, that are not well known and claiming as their own (Buckeridge \& Watts, 2013); stealing a portion or another's writings or ideas that are not well known and claiming as their own (Mahmood et al., 2010); or, copying works created by another and claiming as one's own creation, and or using without crediting the appropriate source (Writing Program Administrators, 2010).

Other definitions of plagiarism exist as well. For example, empirical studies define plagiarism as the taking and utilization of another person's thoughts, writings, ideas, or inventions, and claiming them as one's own; stealing another's writings or ideas and not giving proper attribution; and copying and claiming the ideas or writings of another without crediting the appropriate source (Mahmood, 2010). Any type of information that is not common knowledge to law students should be cited, lest it be considered plagiarism. If law students have a proper understanding of common knowledge and plagiarism, then they should be more adept at properly citing utilized information sources. If students do not properly understand citation, then they are likely to commit plagiarism. Previous research discovered many impetuses for plagiarism.

Many studies convey multifaceted impetuses for student plagiarism. For example, some students do not view certain substantive sources as being important, and thus they commit plagiarism (Austin, Collins, Remillard, Kelcher, \& Chui, 2006). Other studies cited impetuses for committing plagiarism such as failing to seek out guidance about preventing plagiarism from professionals (Beard \& Bawden, 2012), viewing certain assignments as not that important (Aggarwal, Bates, \& Davies, 2002) and possessing a lack of student sophistication (George, Bright, Hurlbert, Linke, \& St. Claire, 2006), or in other words, assumptions that any information located on the Internet did not require attribution. Regardless of the incentive for plagiaristic behavior, such student misconduct occurs frequently whether it is malevolent or due to a form of ignorance. Austin et al. (2006) noted $80 \%$ of respondents on a questionnaire of self-reporting plagiarism admitted to committing plagiarism at least one time. Plagiarism is one factor this study seeks to examine. There are many motivations for plagiarism, and to further understand how this research project was completed the methodology implemented in this study is discussed below.

\section{METHODOLOGY}

This study utilized a diverse population to obtain law student subjects from four separate law schools in Texas. These law schools included South Texas College of Law Houston, Baylor Law School, the University of Texas A\&M School of Law, and Thurgood Marshal School of Law. An online survey and six focus groups were utilized to gather data. The populations of the survey and focus groups were not necessarily the same, so one was unable to make direct conclusions between the data. To ensure reliability and validity of the data collection a pilot study, triangulation, thick description, saturation, and crystallization were implemented. The data was 
scrutinized via thematic analysis and SPSS to complete this study. Subjects for this study were obtained via the snowball effect.

To obtain subjects for the piloting of the online survey, the actual online survey, and the focus groups, the snowball effect and an opt-in procedure were purposely utilized. The snowball effect consists of recruiting one subject willing to participate in your study. Then, relying of that subject to recruit additional subjects for you study. Kisely and Kendall (2011) articulated that when completing qualitative research, sampling was purposive and subjects were recruited who could provide information relevant to the topic of study. This study utilized the snowball effect to gain subjects for the online survey pilot, for the actual online survey, and for the focus groups. First, permission was obtained from the University of North Texas IRB and from the Texas A\&M IRB, and from law school administration at all four law schools to send the online survey to each law student at each respective law school. Subjects were then obtained for the focus groups via convenience, the snowball effect, and an opt-in process by asking law school administration, faculty, and librarians to help recruit students to take the online survey and participate in the focus groups.

To obtain subjects for the focus groups, law school administration, faculty and librarians created a sign-in sheet for students. The first seven first year students were chosen to participate in the first year focus group. The first seven second and third year law students to sign up were chosen for the second focus group. Additionally, administration, faculty, and law students advertised that food and non-alcoholic drinks would be provided for all subjects willing to participate in the focus group. In total, 14 students from each law school (Texas A\&M School of Law, Baylor Law School \& Thurgood Marshall School of Law) were recruited to participate in two separate focus groups at each school. One focus group at each of these schools consisted of first year law students, and the second at each school consisted of second and third year law students. A total of six focus groups were performed, two at each school.

\section{Online Survey}

After finalizing the research queries for the online-survey, a pilot study was completed. First, the online survey was delivered to 30 individuals. All 30 respondents fully completed the online survey and submitted it. The pilot online survey responses were analyzed utilizing Cronbach's alpha and a factor analysis. Use of these statistics confirmed that the survey was valid and reliable. Cronbach's alpha revealed that the online survey resulted in a .6 reliability quotient. A factor analysis also revealed the online survey exhibited a $.7-.9$ construct validity, and based on these statistics, the online survey had solid reliability and validity, and all of the scores were within the normal limit according to Cronbach's alpha.

After crafting and testing the online survey via initial drafting, the pilot study and the modification post-pilot, the online survey was implemented in this study. Spradley and McCurdy (1989) noted that surveys are designed to garner panoply of the subject's native world, or to map the subject's cultural terrain. They further discussed that surveys helped ethnographers demarcate the boundaries of the study, which participated the use of an online survey. The online survey in this study consisted of 24 questions, six of which measured the independent variables: 
age, gender, year in law school, highest level of education, educational environment in which training regarding information literacy was received (high school, college, graduate school), law school environment in which training regarding information literacy was received (e.g., basic research and writing class, moot court...), and law school attended. The survey also consisted of five questions that measured understanding of common knowledge, nine questions that measured citation and common knowledge, and four questions measuring law student source selection.

Focus Groups Card Sorting Technique

Along with an online survey, this study completed six focus groups. Each focus group was conducted in-person and audio recorded. The subjects were located at their respective law school library (e.g., the students participating from Thurgood Marshall School of Law partook at the Thurgood Marshall School of Law Library). I collaborated with each of the three law library directors and the research and writing law professors located at each law school to ensure food and beverages were available for the subjects of each focus group as promised. During the focus group, when saturation occurred, I sought to obtain crystallization in my research findings, which furthered the transferability of my results. Fetterman (2010) noted that crystallization occurs as insights begin to fall into place for ethnographers. Therefore, as saturation of data was manifested in my research, I remained cognizant to notice any crystallization of insights in regard to first, second, and third year law student perceptions of plagiarism, choice of whether to give attribution, and of the information sources first, second and third year law students sought out to resolve information dilemmas. One procedure that helped confirm saturation was occurring was practicing a card sorting technique.

Card Sorting Technique

To further ensure validity and reliability, a card sorting technique activity was offered at the end of each focus group. To complete this task, first, second, and third year law students were presented with five separate scenarios written and conveyed on five separate large pieces of cardboard in which citation may or may not have been required. The law students were asked to sort the scenarios in the order of one to five. One represented the scenario that most required citation to certain legal sources, and five represented the scenario that least required citation. The purpose of this card sorting technique was to further corroborate the data collected from the online survey and from the other focus groups.

\section{RESULTS}

\section{Results from the Survey}

The results of this study suggest law students may exhibit some differences in their understanding of citation and citation behavior based on their age and their year in law school. They also may exhibit some differences regarding common knowledge based on their year in law school and where they received their information literacy training. For example, after running a one way between-groups multivariate analysis of variance, in regard to understanding of citation and citation behavior, statistically significant differences in understanding of citation and citation behavior were gleaned between second year law students and first year law students: $\mathrm{n}=217$, 
$\mathrm{F}(3,61)=5.560, \mathrm{p}=.004$; Tukey HSD $=.047$; and third year and first year law students: $\mathrm{n}=$ $217, \mathrm{~F}(3,61)=5.560, \mathrm{p}=.004$; Tukey HSD $=.007)$. Also, after running a one way betweengroups multivariate analysis of variance, a statistically significant difference manifested regarding understanding of citation and citation behavior between 18-24 year old law students and 25-34 years old law students: $\mathrm{n}=217, \mathrm{~F}(2,62)=4.039, \mathrm{p}=.019$; Tukey HSD $=.014$. Thus this suggests 25-34 year old law students may understand citation better than 18-24 year old law students, and second and third year law students may understand citation better than first year law students. This is logical regarding year in law school in that as one progresses through law school, one should better comprehend the ideas behind citation.

After running a one way between-groups multivariate analysis of variance, statistically significant differences regarding common knowledge were also found between first year law students and third year law students: $\mathrm{n}=232$, F $(3,72)=5.700, \mathrm{p}=.004$; Tukey HSD - .003.. This difference may suggest that third year law students are more likely to view the information queried in this study as common knowledge compared to first year law students. In general, upper law students may have a better understanding of common knowledge compared to first year law students. After running another one way between-groups multivariate analysis of variance, a statistically significant difference regarding common knowledge was also found between law students who claimed they received the best information literacy training in high school compared to those who claimed they received the best information literacy training in graduate school: $\mathrm{n}=232, \mathrm{~F}(3,71)=6.334, \mathrm{p}=.002$; Tukey HSD $=.027$. This finding may suggest that law students who claim to receive the best information literacy training in law school have a better understanding of common knowledge than do law students who claimed to of received their best information literacy training in high school This is logical as well. Data from the focus groups produced insightful information as well.

\section{Results from the Focus Groups}

The data garnered from the focus groups offered some more granular insight into law student information seeking and their understanding of citation, common knowledge, and plagiarism. These findings suggest law students know how to cite print materials, are perplexed about citing digital sources, and at times will ignore the need to cite altogether. They further are often motivated more by fire and brimstone warnings to cite than by simply knowing the proper rules for citation. They also exhibited a strong preference for using Google first to locate legal information because it saved time, money, and is easier to use than Westlaw or LexisNexis. This preference for Google is reinforced by partners in law firms when law students are clerking for these partners in the summer. This preference may reinforce Zipf's (1949) paradigm by which this study is guided. Additionally, law students vehemently avoided citing Wikipedia and other digital sources such as websites, social media, and listservs because they perceived citing such sources equal to losing credibility. Finally, law students viewed plagiarism and common knowledge as contextual. For example, an action that constituted plagiarism in one country may not have constituted plagiarism in another country. The discussion below examines these findings in more detail. 


\section{Preference for Google}

Law students in this study manifested a strong preference to use Google first for most legal research. One reason law students preferred to use Google first when trying to obtain needed information is because law students perceived Google as a tool with which they could quickly obtain access to almost all information. When queried during the focus groups as to what source law students would use first if they could utilize any source to obtain information for law school assignments, law students answered almost unanimously - Google. When prompted as to why they would choose Google first rather than a print case book or statute, or a digital source such as LexisNexis or Westlaw; first, second, and third year law students responded that Google "was fast, it delivered results fast," and "Google delivered an abundance of information quickly a conveniently." Members from a subsequent focus group opined that they preferred using Google as a first research option because Google "quickly retrieved information; it was fast; and accurate." One student added she knew "over the past few years Google has gotten better about finding all information." However she could not provide examples or proof to support such a claim.

A subsequent focus group with law students corroborated this perception of Google as an information panacea when a first year law student opined he used Google "when I am looking up a case for class... because if you put it in Google, then some of the cases will come up. And then sometimes Google will send you to the Supreme Court's site. If I want to make sure I have the right case I go to Lexis." Therefore, students preferred to use Google because they obtain some information quickly and conveniently, regardless of its actual accuracy.

Yet, some law students admitted that they did not know if the information obtained from Google was always correct, hence the comment above, "if I want to make sure I have the right case, I go to Lexis." Another first year student in one of the focus groups stated "I use Google because I can just quickly type it in and get answers, even though I know it's not the most accurate source. I still get a rough idea of what I need to know." Thus, the law students appeared to want to obtain some quick, fast information, even though they realized the information they are receiving may not be all that accurate.

Because of this reticence some law students had that the information they are retrieving from Google is completely accurate, they often utilized Google as a springboard to ultimately obtain needed information from a site they believed was valid such as Westlaw or LexisNexis. For example, they entered a case name or a legal concept into the Google searched the interface and hoped to access a valid case or statute. After obtaining some information from Google, they then attempted to look up the information, often a case or statute, in LexisNexis or Westlaw, to ensure the information they located was valid and reliable. For example, one student noted she looked up legal concepts on Google in hopes to find cases for her law school class. However, she expected that Google would direct her to the Supreme Court's Website ultimately, or she "would look up the case in LexisNexis to make sure it was accurate." So, law students, of all levels; first year, second year, and third year, appeared to use Google first because it instantly provided access to some information, not necessarily valid and reliable information. However, law 
students were sometimes weary of the information retrieved on Google, so they ended up verifying what they located on LexisNexis or Westlaw anyway.

Law students also manifested a preference to primarily use Google when presented with broad and complex topics, and not necessarily narrow concepts, or concepts they believed they understood well. For example, multiple focus groups containing first, second, and third year law students opined that they used Google mainly to search for information about broad topics with which they were not familiar. One third year law student stated he would start with Google "because it is the fastest way you can narrow down if you have no idea where the forest is. It kind of quickly puts you in the right direction at least." A first year law student from another focus group mentioned that "I like to use Google because it narrows down the topics, if it is something complex I am researching or if it is something that is not common knowledge." Another law student agreed and added, "but, if I am familiar with the topic or I know exactly what case I need, I go to Westlaw or Lexis first." Thus, law students may tend to utilize Google first when dealing with broad, complex legal topics with which they are not yet familiar. However, if law students are presented with narrow topics or exact cases to obtain, they may tend to use the commercial databases such as Westlaw or LexisNexis, rather than commence research with Google.

Law students also communicated they tended to use Google to save money. For example, in one focus group a law student opined he was instructed during his internship by a supervising attorney at a law firm to always commence his research with Google. I asked the student why he received this instruction, and he replied "because it is free." He stated that his supervising attorneys instructed him to commence research with Google first, and then if he could not find the necessary information to use a resource like LexisNexis, Westlaw, or another commercial database. The law student said he was given this instruction "because it saved the law firm money," completing legal research on Google is free compared to performing legal research on a commercial database like Westlaw that may bill \$30 per search, \$150 per hour, or a higher fee.

This concept of saving money seems to relate back to the discussion directly above about law students beginning research with Google when broad, complex topics are presented to them. Perhaps attorneys continue this approach when they begin to practice law, and this behavior is reinforced due to Google being a free resource where one may search for solutions to complex legal issues for free for as long as one likes. Then, if a free answer or relevant free information is not obtained quickly, then the attorneys consult the databases from which they can retrieve information for a high fee. One problem with searching for free information on Google is Google only offers less than one percent of information available, in other words Google is not the deep Web. Whereas, LexisNexis and Westlaw offer organized, valid and reliable information that could be utilized to assuage legal information needs. This behavioral reinforcement of using Google first also tends to corroborate Zipf's (1949) paradigm.

\section{Law Student Citation}

Despite their strong preference to use Google, law students seemed to grasp the common reasons of why it was important to cite sources. The conversations with law students during the 
various focus groups magnified that the law students did comprehend why citation was important. For example, when law students were asked why it was important to cite sources, some of the responses received consisted of "if you do not give proper credit, it is plagiarism," "it gives you more strength to your argument," "it shows our arguments are soundly based," and "our law is based on precedent and the common law system, and it's important to cite precedent." Thus, law students, first, second, and third year, seemed to grasp the basic importance of citation - that to cite gave the writer credibility, it gave the reader a roadmap of sources to follow, and it supported the basic premise of our precedential legal system in the United States. In general, the law students (at all levels, first year, second year, and third year) analyzed in this study comprehended the importance of citation and the perils of not citing. A larger concern manifested was that law students in this study demonstrated confusion in regard to properly citing digital information sources. This confusion echoed the previous plagiarism literature mentioned above.

\section{Confusion about Citing Digital Sources}

The data collected in the focus groups revealed that some law students were not aware of how to cite digital sources, or lacked an awareness that they should even cite digital sources. Such digital sources that law students manifested oblivion regarding citation included: websites, Facebook $\left(\right.$, Twitter ${ }^{\mathrm{TM}}$, emails and other digital sites. The American Psychological Association Citation Manual and Modern Language Association Citation Manuals offered guidance on how to cite digital sites. Law students were taught to cite with the Bluebook, it also offered guidance on how to cite digital sites. Yet, they appeared to not know how to cite many digital sources. Other responses revealed lack of understanding of how to cite digital material.

During the focus groups, when asked if law students should cite a digital source if they used such content to craft a brief, one student responded "I am not sure. How do you cite snapchat"M?" Another law student said, "no, if we go on their site, say Facebook, and they are talking about cheese, I am not going to site that." Whereas, law students seemed to understand if they use content from a print source, they would cite it. Another student conveyed if he used information from a blog, email, or Facebook he would not cite because "there isn't really guidance, it is hard to tell." "Like how do you do that kind of citation? Is there a format for that? I don't know. I honestly don't know."

Another student mentioned if he located a pertinent statute on a blog, he would not cite the blog because "you cannot really cite a blog," but instead cite the actual statute," meaning the Westlaw or LexisNexis version of the statute. Another students claimed she "would not cite a blog. Only if I write something word for word off of a blog. If it is something I already know, why would I cite to it? Only cite something unique on the blog. Something I have not thought of before." Another law student opined "I would not cite a listserv, Wikipedia, or a blog." Some law students seem to have a perception that a lot of content on the Internet is just out there and belongs to all and credit does not necessarily have to be given to a creator or to the host site. Other law students who participated in the focus groups also did not know how to cite to digital sites such as blogs, Facebook and websites. This overall lack of knowledge in regard to the necessity of citing digital resources, and the lack of knowledge of how to cite such sources may 
lead to law student plagiarism. Thus, apparently, some law students may be in need of additional instruction in regard to why they should cite digital sources, and how to cite digital sites such as social media, blogs, a listserv, and other digital arenas. Such training could vastly improve law student information literacy. Yet, another theme of a fear of losing credibility when citing digital sources also surfaced.

\section{A Lack of Credibility}

Some of the reticence of citing digital material also seemed to stem from perceiving that such citation would lead to a lack of credibility. For example, during one focus group a discussion manifested regarding whether one could cite social media. The majority of students in this focus group claimed if one cited social media one would lose his or her credibility. For example, one student stated if you cite social media "I think it just ruins your credibility." Another student corroborated this opinion and added "for judges who are reading these documents, half of them don't even know what Twitter is, and the other half don't consider it reliable or good at all." This same student added "people think law and think stuffy old men, honestly. And it is pretty much true. It's changing because people get older and younger people are coming up." So perhaps someday citing social media will evoke credibility? But for now, many law students seemed apprehensive of citing social media due to a concern that citing social media would equate to a lack of credibility in their writing. Another issue that arose from the focus groups was a fear of being caught as a motivator for plagiarism.

Fear of Consequences Trumps Proper Training

Another common theme that arose during the focus groups was that students were not confident in their training regarding citation and plagiarism at any educational level (e.g., high school, college, and graduate school), and a fear of being caught seemed to exist as a primary motivator rather than knowing how to cite correctly. For example, when queried about whether they received good training regarding plagiarism and citation at various levels of education, some of the common responses elicited consisted of: "Sitting here at this table I am learning I did not receive adequate training regarding plagiarism. Like sitting here at this table I've learned I do not know everything I need to cite." A subsequent student noted, "I think I received adequate training, but I think it depends on the amount of punishment your institution puts toward punishment. In undergrad a lot of people went before the board and were punished. I think if people knew they would face those consequences if they plagiarize, they would want to find out more about how not to plagiarize." Therefore, a general theme of a fear of being accused of plagiarism, or suffering the consequences of being caught plagiarizing seemed to exist among law students, rather than a confidence of knowing how to properly cite. In sum, despite the survey response in the online survey that conveyed $64 \%$ of law students believed they received the best training regarding plagiarism and citation in college, their comments in the focus groups revealed they believed, in general, they did not receive good training regarding plagiarism and citation at any level, but instead they were afraid of being caught and punished for plagiarizing. Some of this fear may be related to not knowing how to cite digital sources. 
Another common theme manifested in various focus groups related to fear was holding the honor code and a handbook over students heads rather than specifically conveying to them how not to plagiarize. In regard to not being told how not to plagiarize, a majority of law students in the focus groups indicated they believed they did not receive good citation training from high school through college. They did believe they received better citation training in law school, but still were insecure in their citation abilities in law school. For example, one student proclaimed "during my undergraduate, professors in general just preached the honor code, and anything in violation of honor code and you can be sanctioned and get in to trouble. I think ultimately there is fear of being labeled a plagiarizer, which is something I do not want to be called." Another student opined, with regard to citation training "it was never truly training and explaining, it was go read the handbook, go read the honor code. If you sign an honor code and you start here, you could be in violation of that, but it never was getting to the root of what they were looking for. So I think fear outweighed it." A separate student added "Probably starting in eighth grade, they used turnitin.com to make sure we didn't plagiarize. All that did was terrify me of plagiarism, but didn't really teach me how to actually cite it, except for change enough words where it doesn't look like (plagiarism)... So, all through eighth grade on, I've just been scared of plagiarizing. It's definitely about fear." Additionally, another student conveyed "I think the fear was the training. They didn't really tell us. They just always said, don't plagiarize, they never said here is how to differentiate between the two." In essence, the majority of students in the focus groups indicated that fear may have motivated them to cite more than receiving proper training about what exactly plagiarism was, or how to prevent plagiarism. Thus, perhaps, law schools, and even colleges need to offer more information literacy training specifically focused on what plagiarism is and how to prevent plagiarism with the use of a citation manual.

Plagiarism is Contextual

Another interesting common theme that arose from multiple focus groups was the idea that plagiarism was contextual based on geography and political or cultural norms. For example, one law student pointed out she grew up in Macedonia and that there "Communism was valued and everything was collectively owned...," and therefore "during her education they did not make much point of plagiarism." "Instead they were focused on the signs and substance versus citing correctly." She added that in Communism "everything is common property, it was an idea that you are valuable but your contributions belong to all of us." Finally, she conveyed "I don't think there was any instruction in Greece either, where half of my family lived." This cultural, political, and geographical bias toward acceptance of plagiarism is supported by the research completed by Meyer (2007) who utilized interviews and observations of a sample of 155 Russian speaking students and discovered these Russian students adhered to krugovaya poruka, or the exchanging and sharing of everything.

In other words, the results of this study may suggest and corroborate previous empirical propositions that plagiarism was an accepted practice in certain cultures, such as in some Russian collectivist cultures (Meyer, 2007). Thus, the data collected in this study tends to support the theory that geography, culture, and political norms can influence the perception of plagiarism. It 
also supports Zipf's (1949) paradigm that when possible and if acceptable, humans will take the easier approach.

Other data collected during focus groups in this study reinforced this geographic, cultural, and political slant on perceptions of plagiarism. During one of the focus groups, a student commented he studied undergraduate work in Mexico, and "no one ever mentioned plagiarism." He further conveyed "I want to add I think plagiarism is cultural." He further stated that there was never any instruction about how not to plagiarize in Mexico. He also stated "I think Mexico is different with plagiarism because the legal system in America is based on precedents. We base decisions of what the higher court decided. We only know about it if we cite it." In summary, it appears some law students may have believed the concept of plagiarism being acceptable or not depended on where one lived, and the cultural and political norms. Such thought was supported by other research on plagiarism (Meyer, 2007; Keyes, 2004). Yet, based on the data collected in the focus groups, law students in Texas seemed to understand and agree that plagiarism, in general, was not culturally acceptable in the United States. Several possible future studies result from the findings of this research.

\section{Future recommendations}

A plethora of recommended future research emanates from this study. Future studies need to be performed to decipher in granular detail why law students specifically do not understand how to provide attribution or shy away from citing certain digital information sources when they extract information from these sources and use it in their law school assignments. Future studies need to be implemented to discover what other granular reasons exist as to why law students prefer Google. In other words, are their other reasons for this preference other than saving time and money, being digital natives, and just simply being used to utilizing Google to locate information? For example, is there a problem with other digital interfaces, such as Westlaw and LexisNexis juxtaposed to the Google interface? Do students realize when they are using Google, compared to Westlaw and LexisNexis, that they are only garnering one percent of the information available regarding specific legal topics?

A future study examining why law students view the necessity for proper citation as contextual, and why law students perceive plagiarism as contextual is needed as well. This study manifested law student views that plagiarism and citation are contextual. Some of the reasons law students conveyed to support this perception included, what is plagiarism in one culture, country, state, or even a classroom, may not be plagiarism in a separate culture, country, state, or even a classroom. Some previous research supports this notion. Meyer (2007) utilized interviews and observations of a sample of 155 Russian speaking students and discovered Russian students adhered to krugovaya poruka, or collective cheating. In other words, the results of this study suggested that plagiarism was an accepted practice in certain cultures, such as in some Russian collectivist cultures (Meyer, 2007). Keyes (2004) research illustrated that deception is less vilified by some societies as well. Thus, this literature suggested that culture and one's perception of the source from which they are obtaining the information may help determine whether one chooses to give appropriate attribution or not. 
An additional study should examine whether students at the junior high, high school, college and graduate level have this confusion regarding how to cite digital sources. Is there a progression from junior high to high school, or high school to college that indicates as students progress through their education that they have a better grasp of how to cite digital sites and sources? Or, is their mass confusion at all levels. Is there such confusion in other substantive areas of study? Such as, are engineering students as confused as law students? Are nursing students facing this same perplexity compared to law students?

A separate study could examine whether this is a confusion between format or source. This study indicated that law students tended to be confused how and whether to cite certain electronic sites such as Facebook, Snapchat, Wikipedia and blogs written by professors. This study also manifested a strong desire not to cite Wikipedia. Therefore, a future study should be performed to determine whether law students do not want to cite any digital sources, or is it that law students are taught not to or do not want to cite just some specific digital sites such as Wikipedia.

Another interesting study that deserves proposing as a consequence of this study is juxtaposing whether students are motivated to offer proper citation due to receiving solid information literacy instruction at the junior high, high school, college, or graduate level; or whether they are motivated to offer proper citation due to a fear of the potential consequences of being caught committing plagiarism. In this study, many law students admitted they did not understand enough about how to cite utilized works, and they were more motivated to cite out of fear of being caught than to give the reader a guideline to future works or to give credit to the original creator. In some cases, the law students admitted they would not give proper citation if they believed there was no possibility of negative ramification of not giving proper citation. For example, one law student opined "I know if I copied and pasted something and give it to my professor, and say this is mine, then I'm going to be in danger of plagiarism." But if it's not in danger of plagiarism, I feel like it's a lot easier for us to be like that's okay I'm not going to figure out how to cite this. Then it is easier to be like this is common knowledge when there is no danger of plagiarism, especially when the stakes are lower." Then, when posed with the question - if this was an assignment that was not going to be graded, would you give proper citation? The students responded "oh no," and "I am defiantly erring on the side of not citing." A subsequent student mentioned "I think you write to your audience. If I were writing for a partner in a law firm, like in an internship, I'm probably not going to feel as compelled to cite, because I know that they are just going to want to know the information." Meaning, they often calculated whether they needed to cite works they used in various documents.

Thus, it would be interesting to juxtapose two groups of law students, convey to one group there will be specific consequences if they do not complete certain information literacy components on an assignment. Then, communicate to the second group that there are no ramification for completing information literacy requirements. A t-test could determine if statistically significant difference exist between the two groups.

Another study that is in need based on the data collected in this study, is one that examines at the granular level why law students never cite Wikipedia when they admit they take information from the Wikipedia site. This study revealed instead of citing Wikipedia, the law students may 
choose to instead just not cite anything, or find a subsequent information source with similar information that is on the Wikipedia cite and cite that subsequent information source.

This study revealed, in general, that law students seemed to view Wikipedia as a source with no credibility. For example, some of the comments law students made about Wikipedia include "it is OK to use Wikipedia or another website, but not cite it. It is not a credible cite. Instead, go to the bottom of the Wikipedia page, and use those citations instead." A subsequent law student noted, "you should never cite Wikipedia because it is a crappy source." Another law student in separate focus groups stated even if you read something you want to use off of Wikipedia, "you can still find the same information in a better source." A separate student stated that if he located the four elements of negligence on Wikipedia, he would not give citation to Wikipedia, but instead would cite a statute that contained the same or similar material. Another student suggested if you find useful information on Wikipedia, "do not cite to Wikipedia, just use the citations at the bottom of the page." Additionally, a first year law student claimed even if she used information directly from Wikipedia she would never cite to it because it is not trustworthy and not credible in court."

This study further revealed that the two main reasons law students developed this perception of Wikipedia is because their law professors and college professor conveyed to them to never use or cite Wikipedia. Also, at least one of the law students suggested she saw a judge admonish an attorney for citing Wikipedia in a legal brief. Yet, almost all of the law students admitted they often went to Wikipedia to learn about legal issues pertaining to their law school assignments and tests. The large majority also admitted they took information from Wikipedia and placed it in their law school assignments that they submitted for a grade. Instead of citing Wikipedia, they cited a similar source. So, a future study needs to be performed with law students and law faculty to determine whether it is really showing a lack of credibility to cite Wikipedia, when students are using the source on a regular basis anyway. Also, the future study should examine why Wikipedia is viewed as an incredible source? Is it really that much more incredible juxtaposed to a print encyclopedia. After all, Wikipedia can be edited in seconds, whereas a print encyclopedia will take months or years to edit.

Another theme that manifested from the online survey responses and the focus group response was that many law students fervently believed if they cited a website, blog, or other digital source that listed a statute or excerpt of a case, even if the wording was the same word-for-word as it appeared in Westlaw, LexisNexis, or a print publication, they would not cite the website, blog, or other digital source in a law school assignment. Neither would they cite such a source in a legal document to be filed with a court. This makes sense in that law students are trained to cite to primary sources (case law, statutes, regulations...), and are taught to cite to those materials found in a publication created by a reputable publisher (e.g., Westlaw, LexisNexis, the United States Government...). This tendency to be reticent to cite other digital sources is also explainable because courts have routinely expected attorneys to cite only to specific print publications published by specific publishers (Westlaw, LexisNexis...) for decades. However, with the rapid evolution regarding how all information is being conveyed and the types of digital platforms on which this legal material is being conveyed, a future study should be performed to 
decipher whether these newer mediums are really less reliable and valid than the Westlaw and LexisNexis publications. For example, is a statute located on a professor's blog really less reliable than the exact stature located in a Westlaw print publication? A study has never been completed to decipher if there is a statistical difference in older and new mediums conveying information.

This study also revealed that law students are perplexed about how to cite digital sources. For example, during one focus groups, when asked if law students should cite a digital source if they use content from that source to craft a brief, one student responded "I am not sure. How do you cite snapchat?" Another law student said, "no, if we go on their site, say Facebook, and they are talking about cheese, I am not going to site that." Whereas, law students seem to understand if they use content about cheese from a print source, they would cite it. Another student conveyed if he used information from a blog, email, or Facebook he would not cite because "there isn't really guidance, it is hard to tell." "Like how do you do that kind of citation? Is there a format for that? I don't know. I honestly don't know."

However, ample guidance exists in the Bluebook, American Psychological Association Citation Manual, and other citation manuals in regard to citing digital sources. A future study should be conducted to learn the reasons why law students are not familiar with how to cite digital sources, determine if they are aware of any publication manuals that direct them in citing digital sources, and decipher whether the legal environment is open to citing various digital sources.

\section{CONCLUSION}

In summation, the data gathered in this study suggested law students may exhibit some differences in understanding of citation and citation behavior based on age and their year in law school. They also exhibit some differences regarding common knowledge based on their year in law school and where they received their information literacy training. For example, this study suggests 25-34 year old law students may understand citation better than 18-24 year old law students, and second and third year law students may understand citation better than first year law students. Also, the study results suggest that upper class law students may be more likely to view the information queried in this study as common knowledge compared to first year law students. Thus, in general, upper year law students may have a better understanding of common knowledge compared to first year law students. Further, the results suggest that law students who claim to receive the best information literacy training in graduate school may have a better understanding of common knowledge than do law students who claimed to have received their best information literacy training in high school.

Interestingly, there were no statistically significant differences regarding citation and information source selection between the four law schools analyzed. The data garnered from the focus groups tended to corroborate that there was no difference between the students from three of the separate law schools (Baylor School of Law, Texas A\&M University School of Law, and Thurgood Marshall School of Law) in that they all seemed to prefer to choose Google as their primary information sources, if they could locate needed information from that source. Then, 
they would utilize the electronic databases such as LexisNexis or Westlaw. Finally, they would utilize the print statutes, case law, or other print sources as a last resort.

The data garnered from the focus groups also suggested law students know how to cite print materials, are perplexed about citing digital sources, and at times will ignore the need to cite altogether. They further are often motivated more by fire and brimstone warnings to cite than by simply knowing the proper rules for citation. They also exhibited a strong preference for using Google first to locate legal information because it saves time and money, and it is easy to use. Additionally, law students vehemently avoided citing Wikipedia and other digital sources such as websites, social media, and listservs because they perceived citing such sources equal to losing credibility. Finally, law students viewed plagiarism and common knowledge as contextual. For example, an action that constitutes plagiarism in one country may not have constituted plagiarism in another country.

A plethora of recommended future research emanates from this study. For example, future studies need to be performed to decipher in granular detail why specifically law students shy away from citing certain digital information sources when they extract information from these sources and use it in their law school assignments. Also, future studies need to be implemented to discover what other granular reasons exist as to why law students prefer Google. In other words, are their other reasons for this preference other than saving time and money, being digital natives, and just simply being used to utilizing Google to locate information? For example, is there a problem with other digital interfaces juxtaposed to the Google interface? Do students realize when they are using Google, compared to Westlaw and LexisNexis, that they are only garnering one percent of the information available regarding specific legal topics?

\section{REFERENCES}

Academic integrity at MIT: A handbook for students. (2014). Retrieved

fromhttps://integrity.mit.edu/citing-your-sources/what-common-knowledge

Aggarwal, R., Bates, I., \& Davies J. G. (2002). A study of academic dishonesty among students at two pharmacy schools. Pharmaceutical Journal, 269(7219), 529-533.

Association of College and Research Libraries (ACRL). (2000). Information literacy competency standards for higher education. Retrieved from http://www.ala.org/acrl/standards/informationliteracycompetency

Austin, Z., Collins, D., Remillard, A., Kelcher, S., \& Chui, S. (2006). Influence of attitudes toward curriculum on dishonest academic behavior. American Journal of Pharmaceutical Education, 70(3), 50. Retrieved from http://www.ncbi.nlm.nih.gov/pmc/articles/PMC1636956/

Beard, C., \& Bawden, D. (2012). University libraries and the postgraduate student: Physical and virtual spaces. New Library World, 113(9/10), 439-447. doi: 10.1108/03074801211273911

Buckeridge, J. S., \& Watts, R. (2013). On ethics, the pursuit of knowledge, truth and status in the hallowed halls of academe. Integrative Zoology, 8, 223-231. doi: 10.1111/j.1749-

4877.2012.12007.x 
George, C., Bright, A., Hurlbert, T., Linke, E., \& St. Claire, J. (2006). Scholarly use of information: Graduate students information seeking behavior. Information Research, 11(4). Retrieved from http://InformationR.net/ir/11-4/paper272.html

Keyes, R. (2004). The post-truth era: Dishonesty and deception in contemporary life. New York, NY: St. Martin's Press.

Mahmood, S. T., Mahmood, A., Khan, M. N., \& Malik, A. B. (2010). Intellectual property rights: Conceptual awareness of research students about plagiarism. International Journal of Academic Research, 2(6), 193-198.

Partin, G. A., \& Wise S. H. (2016). Hitting the mark: AALL legal research competencies: Classroom to practice. AALL Spectrum (March/April 2016). Retrieved fromhttp://www.aallnet.org/mm/Publications/spectrum/archives/Vol-20/No-4/Feature- Hittingthe-Mark.pdf

Writing Program Administrators (2010). Defining and avoiding plagiarism: The WPA statement of best practices. Retrieved from http://wpacouncil.org/node/9

Zipf, G. (1949). Human behavior and the principle of least effort: An introduction to human ecology. New York, NY: Addison-Wesley. 